\title{
Tratamento cirúrgico de fratura severa de ossos próprios do nariz: relato de caso
}

\author{
Surgical treatment of nasal bone severe fracture: case report \\ Tratamiento quirúrgico de la fractura severa del hueso nasal: \\ presentación de un caso
}

\author{
Gabriel Mulinari DOS SANTOS \\ William Ricardo PIRES \\ Leonardo Freitas SILVA \\ Ciro Borges Duailibe DE DEUS \\ Gustavo Antonio Correa MOMESSO \\ Tárik Ocon Braga POLO \\ Francisley Ávila SOUZA \\ Idelmo Rangel GARCIA JÚNIOR \\ Leonardo Perez FAVERANI
}

Faculdade de Odontologia de Araçatuba, Universidade Estadual Paulista, UNESP

16015-050 Araçatuba-SP, Brasil

\begin{abstract}
Resumo
As fraturas nasais são as fraturas mais frequentes em face, esse fato ocorre devido a proeminência dos ossos próprios do nariz (OPN) em relação a face, que faz com que eles possam receber o primeiro impacto frente a um trauma. As fraturas nasais (FN) podem ter seu tratamento cirúrgico ou não, de acordo com a condição estética e também funcional do paciente. O presente trabalho tem como objetivo relatar um caso clínico de um paciente de 30 anos, sexo masculino, leucoderma, vítima de agressão física, admitido na Santa Casa de Misericórdia de Araçatuba relatando sangramento nasal abundante, dificuldade respiratória e dor em face. Ao exame clínico notou-se rinoescoliose significativa á direita e impermeabilidade das vias aéreas, e no exame de imagem por tomografia computadorizada observou fratura OPN envolvendo fratura e desvio de septo nasal. Pelas condições apresentadas no exame clínico e de imagem, foi proposto tratamento cirúrgico sob anestesia geral. A primeira etapa cirúrgica foi realizada com reposição dos fragmentos, seguida do tamponamento para sustentação com tamponamento, porém sem sucesso estéticos e funcionais. A segunda etapa cirúrgica foi realizada sob anestesia geral, com redução da fratura, do desvio de septo e tamponamento. No pós-operatório foi possível notar um resultado satisfatório funcional com patência das vias aéreas e também estético, quando comparado com imagens fotográficas do paciente prévias ao trauma.
\end{abstract}

Descritores: Fraturas Ósseas; Fixação de Fratura; Traumatismos Faciais.

\begin{abstract}
Nasal fractures are the most frequent fractures in the face, this fact occurs due to the prominence of the own bones of the nose (OPN) in relation to the face, which causes them to receive the first impact in front of a trauma. Nasal fractures (FN) may have their non-surgical or surgical treatment, according to the aesthetic and also functional condition of the patient. The present study aims to report a clinical case of a 30 year - old male patient, leucoderma, a victim of physical aggression, admitted to Santa Casa de Misericórdia de Araçatuba, reporting abundant nasal bleeding, respiratory distress and face pain. The clinical examination showed significant rhinosinusis on the right and airway impermeability. On the CT scan, an OPN fracture involving fracture and nasal septum deviation was observed. Under the conditions presented in the clinical and imaging examination, surgical treatment was proposed under general anesthesia. The first attempt was made with replacement of the fragments, followed by the buffering to support with buffering, but without aesthetic and functional success. A second attempt was performed under general anesthesia, with fracture reduction, septal deviation and tamponade. In the postoperative period, it was possible to notice a satisfactory functional result with patency of the airways and also aesthetic when compared to the patient's photographic images prior to the trauma.

Descriptors: Fractures, Bone; Fracture Fixation; Facial Injuries.
\end{abstract}

\section{Resumen}

Las fracturas nasales son los fracturas más comunes en la cara, este hecho es debido a la prominencia de los huesos nasales (OPN) en relación a la cara, lo que les lleva a recibir el primer impacto ante un trauma. Las fracturas nasales (FN) pueden tener su tratamiento no quirúrgico o quirúrgico, de acuerdo con la condición estética y también funcional del paciente. Este estudio tiene como objetivo presentar un caso de un paciente masculino de 30 años de edad, leucoderma, víctima de la agresión física, admitido en la Santa Casa de Misericórdia de Araçatuba informes abundantes hemorragias nasales, dificultad para respirar y dolor en la cara. La exploración física mostró desviación lateral derecha del tabique y el ajuste de las vías respiratorias, como en imágenes de tomografía computarizada por fractura observada OPN que implica la fractura y desviación del tabique nasal. Las condiciones que se presentan en el examen clínico y de imagen, propusieron tratamiento quirúrgico bajo anestesia general. Se hizo el primer intento de cambiar la posición de los fragmentos, seguido por la precarga para el apoyo de amortiguación, pero sin éxito estético y funcional. Un segundo intento fue realizado bajo anestesia general, la reducción de la fractura, el tabique desviado y taponamiento. Después de la operación fue posible observar un resultado funcional satisfactorio con la permeabilidad de la vía aérea y también estético en comparación con las imágenes fotográficas de la paciente antes de la trauma.

Descriptores: Fracturas Óseas; Fijación de Fractura; Traumatismos Faciales.

\section{INTRODUÇÃO}

A face é a região mais exposta do crânio, e devido sua projeção, o nariz esta sujeito a injúrias provocadas por impactos diretos como choques, golpes e quedas. As fraturas da pirâmide nasal tem um alto número de frequência, sendo que aproximadamente $39 \%$ das fraturas buco-maxilo-faciais são nasais ${ }^{1}$. As fraturas nasais estão em terceiro lugar na incidênciade todas as fraturas que ocorrem no corpo humano em traumas desportivos, depois das fraturas da clavícula e 
do punho $^{2}$.

O nariz apresenta estrutura composta por pequena porção óssea, constituída por ossos próprios da pirâmide nasal, lâmina perpendicular do etmóide e vômer. $\mathrm{O}$ nariz apresenta ainda um conjunto de várias cartilagens que conferem, além de permeabilidade às fossas nasais, sustentação à ponta do nariz ${ }^{3}$.

$\mathrm{O}$ diagnóstico das fraturas nasais acontece por meio do exame físico com palpação do dorso do nariz e rebordo orbitário, avaliar crepitações, e se há fragmentos justapostos ou sobrepostos, presença de algesia, rinoscopia anterior e avaliar desvio de septo, crostas ou hematoma septal, e também se faz uso de exames de imagem com radiográfias em incidência de Perfil de Face, Pós-Anterior de Waters e tomografia computadorizada ${ }^{4}$.

O tratamento inicial visa a hemostasia em casos de epistaxe, controle e regressão do edema realizando compressa fria, prescrição de analgésico e descongestionante nasal. As indicações de tratamento são: fraturas que apresentem desvios e/ou instabilidade com queixa estética e/ou funcional. Os melhores resultados tanto estéticos como funcionais se dão sobretudo dentro dos primeiros 15 dias do trauma. Já se os fragmentos estiverem justapostos, o tratamento é conservador ${ }^{4,5}$. No tratamento cirúrgico para reposição dos fragmentos, a redução pode ser aberta ou fechada ${ }^{1}$. Onde se reserva a redução fechada quando no caso de fraturas unilateral ou bilateral de ossos nasais, com desvio menor que a metade da profundidade da ponte nasal. Já a redução aberta é utilizada nos casos de fratura-desvio extensa do osso nasal e septo, com o desvio da pirâmide nasal excedendo metade da profundidade da ponte nasal, além da fraturadesvio do septo caudal, fraturas septais abertas, deformidade persistente após redução fechada ou deformidade combinada do septo nasal e da cartilagem $\operatorname{alar}^{1,4,5}$

Diante disso, a fim de facilitar o diagnóstico e também o planejamento cirúrgico Rohrich \& Adams $^{6}$ mencionam cinco níveis de trauma ao arcabouço nasal. O tipo 1 corresponde à fratura unilateral simples, o tipo 2 à bilateral, o tipo 3 às fraturas cominutivas, o tipo 4 a lesão septal associada e o tipo 5 às fraturas naso-orbitoetmoidais ${ }^{6}$.

As possíveis complicações que podem acontecer em fraturas OPN são: obstrução nasal crônica, desvio de septo e de pirâmide nasal, hematoma septal, infecção local, epistaxe e rinoliquorréia ${ }^{7}$.

\section{CASO CLÍNICO}

Paciente de 30 anos, sexo masculino, leucoderma, vítima de agressão física, admitido na Santa Casa de Araçatuba relatando sangramento nasal abundante, dificuldade respiratória e dor em face. Ao exame clínico notou-se rinoescoliose significativa á direita e impermeabilidade das vias aéreas (Figura 1), já no exame de imagem por tomografia computadorizada observou fratura OPN cominuta em conjunto com o desvio de septo nasal (Figura 1), classificada segundo Rohrich, Adams ${ }^{6}$ como tipo 4 por apresentar lesão septal associada ${ }^{6}$. Pelas condições apresentadas no exame clínico e de imagem, foi proposto tratamento cirúrgico fechado sob anestesia geral e intubação orotraqueal. A primeira tentativa foi realizada com reposição dos fragmentos por meio do auxílio de um elevador, seguida do tamponamento por 72 horas para sustentação e suporte, porém o paciente ainda permaneceu com queixas estéticas e funcionais, após 7 dias em retorno ambulatorial (Figura 2). Uma segunda tentativa foi relizada sob anestesia geral e intubação orotraqueal, com redução da fratura e do desvio de septo com uso do fórceps de Asch, seguido do tamponamento por 72 horas. No pós-operatório de 15 dias foi possível notar um resultado satisfatório funcional com patência das vias aéreas e também satisfatório clinico e funcional, com ausência de queixa estética do paciente (Figura 3).
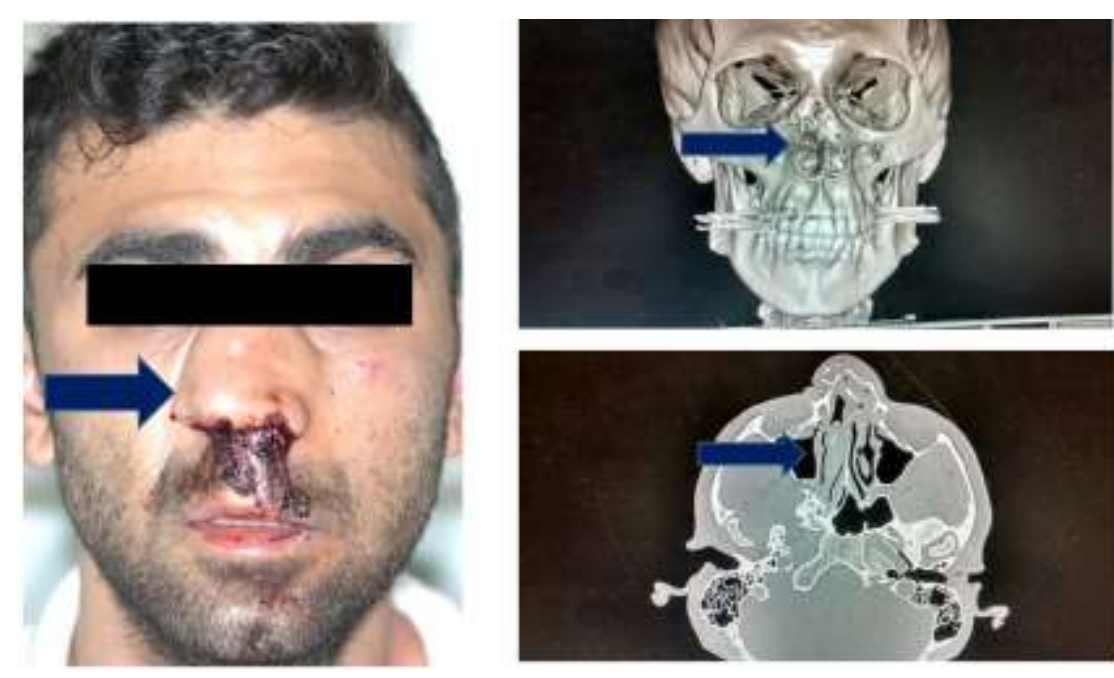

Figura 1: Pré-operatório. Exame clínico nota-se rinoescoliose à direita e exame de imagem com tomografia computadorizada em reconstrução 3D e corte axial evidenciando fratura OPN com envolvimento de septo nasal.
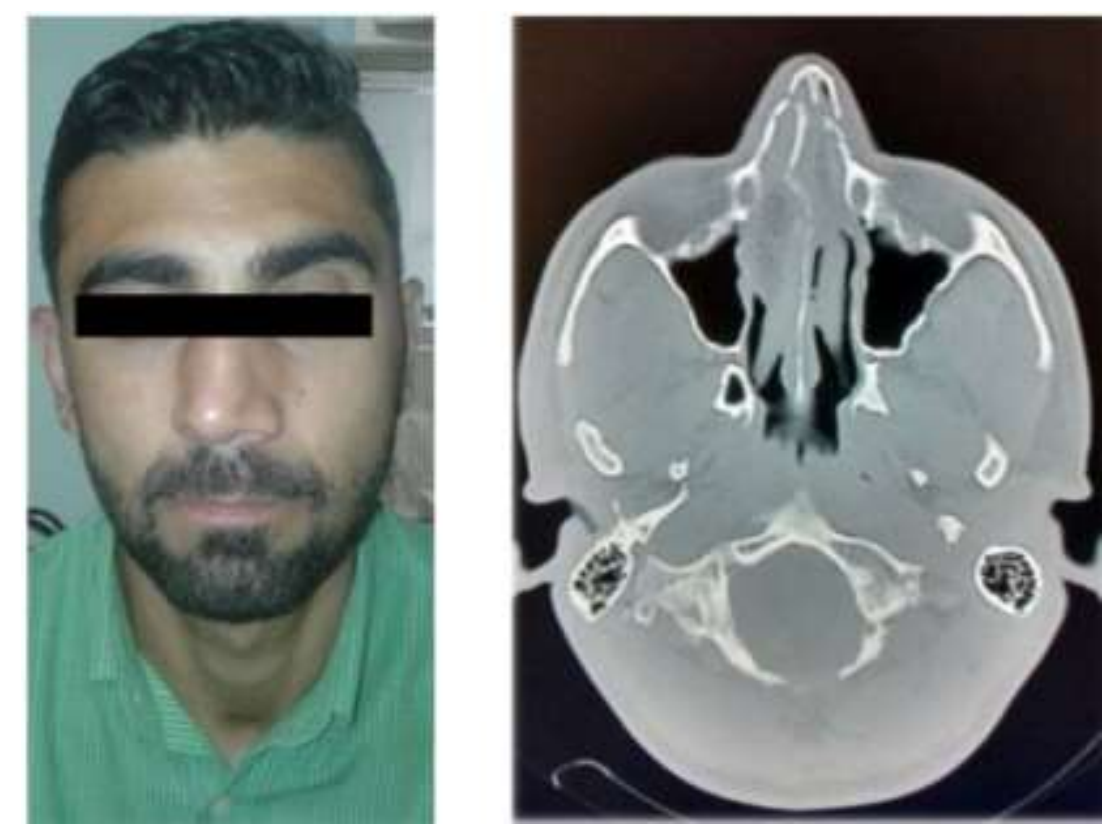

Figura 2: Pós-operatório de 7 dias após a primeira tentativa de redução, com tomografia computadorizada em corte axial e exame clínico do paciente, o qual ainda permanecia com queixa estética e funcional.
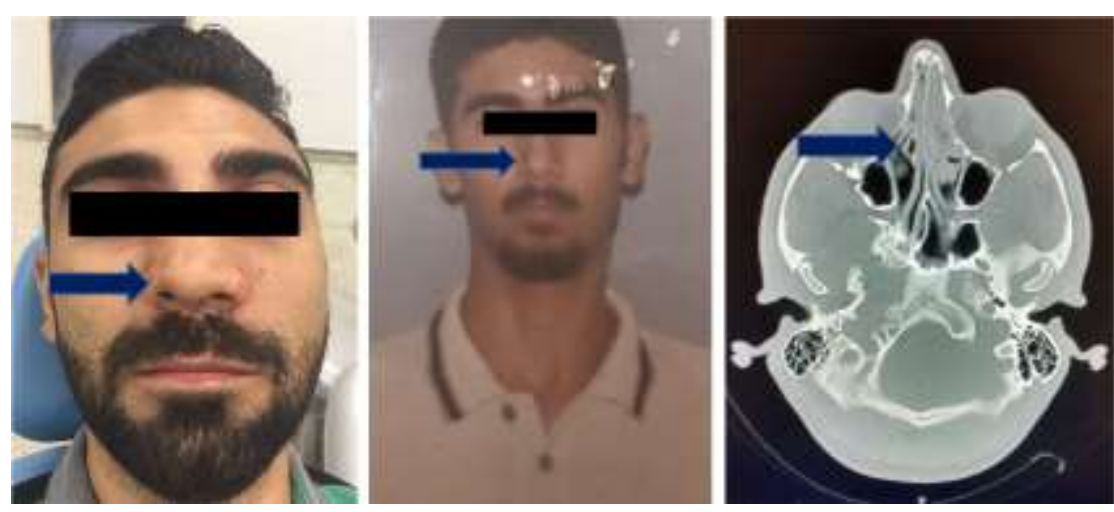

Figura 3: Pós-operatório de 15 dias após a segunda tentativa de redução, e imagem do paciente antes do trauma onde é possível notar uma rinoescoliose a direta prévia, tomografia computadorizada evidenciando o correto posicionamento dos ossos próprios nasais e do septo nasal após a segunda redução.

\section{DISCUSSÃO}

A manipulação das fraturas nasais pode ser realizada por redução fechada, com uso de instrumentação e sem incisões, ou por redução aberta por meio de incisões e manejo aberto dos ossos nasais e do septo.

A opção de abordar uma fratura OPN com redução aberta ou fechada ainda é controversa. No caso exposto, o 
tratamento proposto foi realizado com redução fechada, na tentativa de reduzir e estabilizar a fratura nasal do tipo 4 segundo classificação de Rohrich, Adams ${ }^{6}$. A redução fechada esta indicada para casos de fraturas unilateral ou bilateral de ossos nasais, com desvio menor que a metade da profundidade da ponte nasal ${ }^{1}$, como presente neste trabalho. Autores citam que a redução da fratura também pode acontecer sob anestesia local ou geral, variando de acordo com as características do paciente e aptidão do cirurgião ${ }^{7,8}$. Optou-se nesse caso por realizar a redução sob anestesia geral, visto que o próprio paciente relatou alterações emocionais e intolerância acentuada à dor.

Outro estudo revela que obteve melhores resultados, com média de satisfação funcional e estética de $86 \%$ e $84 \%$, respectivamente, após redução fechada tanto por anestesia geral quanto por local ${ }^{9}$.

$\mathrm{O}$ tratamento cirúrgico das fraturas OPN está indicado quando há presença de fraturas com deslocamentos significativos, associados ao comprometimento da patência da via aérea, assim como defeitos estéticos, como queixa no presente relato $^{10,11}$.

A documentação fotográfica também é um fator útil no diagnóstico das fraturas nasais, onde se pode observar a já existência ou não de deformidades nasais antes da atual injúria $^{12}$, como no caso apresentado, onde o paciente já possuia uma rinoescoliose a direita prévia ao trauma.

Com o tratamento cirúrgico proposto foi possível notar o correto re-posicionamento do nariz, , podendo observar o bom aspecto pós-operatório de 15 dias, sem sinais e sintomas de infecção, e com discreto edema compatível ao do procedimento cirúrgico realizado.

\section{CONCLUSÃO}

Com base no exposto, pôde-se concluir que a redução fechada para restabelecer o adequado posicionamento e projeção em fraturas nasais mesmo com grandes deslocamentos e envolvendo septo nasal, é possível conferindo também melhores condições funcionais e estéticas ao paciente.

\section{REFERÊNCIAS}

1. Bailey BJ. Head and Neck Surgery-Otolaryngology. Philadelphia: JB Lippincott Company; 2001. vol. 1, cap.65-69.

2. Dingman RO, Natvig P. Cirurgia das fraturas faciais. São Paulo: Santos; 2001. p. 267-94.

3. Rizzolo RJC, Madeira MC. Anatomia Facial com fundamentos de Anatomia Geral. 3.ed. São Paulo: Sarvier; 2009

4. Peterson LJ, Ellis E, Hupp JR. Cirurgia Oral e Maxilofacial Contemporânea. $3^{\mathrm{a}}$ ed. Rio de Janeiro: Guanabara Koogan; 2000. p. 487-511.

5. Miloro M, Ghali GE, Larsen PE, Waite PD. Princípios de cirurgia bucomaxilofacial de Peterson. $2^{\mathrm{a}}$ ed. São Paulo: Santos; 2008. p. 435- 462.

6. Rohrich RJ, Adams WP Jr. Nasal fracture management: minimizing secondary nasal deformities. Plast Reconstr Surg. 2000; 106(2):266-73.

7. Manganello-Souza LC, Luz JGC. Tratamento Cirúrgico do Trauma Bucomaxilofacial. $3^{\mathrm{a}}$ ed, São Paulo: Roca; 2006.

8. Vetter JD, Topazian RG, Goldeberg MH, Smith DG. Facial fractures occuring in a medium-sized metropolitan area: recent trends. Int J Oral Maxillofac Surg. 1991; 20(4):214-6.
9. Rajapakse Y, Courtney M, Bialostocki A, Duncan G, Morrissey G. Nasal Fractures: Astudy comparing local and general anaesthesia techniques. ANZ J Surg. 2003; 73(6):396-9.

10. Dingman RO, Natvig P. Cirurgia das fraturas faciais. 3 ed. São Paulo: Santos; 2004.

11. Ziccardi VB, Braidy H. Management of Nasal Fractures. Oral Maxillofacial Surg Clin North Am. 2009; 21(2):203-8

12. Monnazi MS, Oliveira HC, Passeri LA, Gabrielli MFR. Manejo das fraturas nasais com manutenção das vias aéreas superiores. Rev Cir Traumatol Buco-Maxilo-Fac. 2010; (10):55-60

13. Yoon T, Kim Y. Postoperative satisfaction in nasal bone fracture patients who had rhinoplasty. J Craniofac Surg. 2016; 27(7):1707-10.

\section{CONFLITO DE INTERESSES}

Os autores declaram não haver conflitos de interesse.

\section{AUTOR PARA CORRESPONDÊNCIA}

Gustavo Antonio Correa Momesso

gustavomomesso@gmail.com

Submetido em 13/02/2017 Aceito em 01/03/2017 